\title{
Motivational influences on word recognition: III. Parafoveal processing differs from foveal processing
}

\author{
EVA DREIKURS FERGUSON \\ Southern Illinois University, Edwardsville, Illinois
}

\begin{abstract}
Food words and negatively emotional words were presented in one visual field at a time (Experiments 1 and 2) or in two visual fields concurrently (Experiments 3 and 4), in order to enable us to assess (1) to what extent motivation and word characteristics affect parafoveal and foveal word processing in comparable ways and (2) whether differences between parafoveal and foveal processing are due primarily to the initial encoding of a word by a single hemisphere or by two hemispheres. Motivation in interaction with word category had a significant effect only when viewing was partly foveal (Experiment 3). Moreover, the initial encoding of the words by two hemispheres, as opposed to one, could not account for clear-cut differences between parafoveal and foveal processing. Word characteristics effects, when significant, were evident only for rightfield processing, and not for left-field processing.
\end{abstract}

A series of tachistoscopic studies by Ferguson (Erwin \& Ferguson, 1979; Ferguson, 1983, 1988, 1989) employed an information-purchasing procedure, in which words were projected briefly and repeatedly until correctly recognized. The dependent variable was the number of presentations or trials (how much information had to be purchased) that were required for correct word recognition. These studies revealed that hunger as an approach motivation facilitates word recognition under foveal, but not parafoveal, viewing. Word category was found to have a significant effect on foveal word processing (Erwin \& Ferguson, 1979; Ferguson, 1983) and, under somewhat longer exposure durations, on parafoveal processing (Ferguson, 1989). Several questions remain concerning possible differences between parafoveal and foveal word processing. For example, even when affective word content did have a significant effect on parafoveal word recognition, why did motivation nevertheless still fail to have a significant effect? It is also not clear what role word and interletter associative frequency play. The earlier foveal studies had found that word frequency, measured by the Thorndike and Lorge (1944) count, and interletter associative frequency, measured by the generated value of Underwood and Schulz (1960), had a predictable significant effect: high interletter frequency and frequent words require significantly fewer presentations for recognition. Whether or not word and interletter frequency have a comparable effect on parafoveal word processing still needs to be determined.

\footnotetext{
Grateful acknowledgment is given to the Research and Projects Office, Southern Illinois University at Edwardsville, for continued support of this research. Correspondence should be addressed to Eva Dreikurs Ferguson, Psychology Department, Southern Illinois University, Edwardsville, IL 62026-1121.
}

The research literature on reading has provided some evidence to suggest that parafoveal and foveal word viewing tap different underlying processes, with word category and word frequency possibly having different effects under the two types of viewing conditions (Balota, 1990; Balota \& Rayner, 1991). Unlike the procedure of the present information-purchasing type of tachistoscopic study, the procedure in reading studies typically requires subjects to view words concurrently, some foveally and others parafoveally. Whether the two types of viewing tap different underlying processes when only one word is viewed at a given time is still not fully clear.

Only a single hemisphere initially encodes the stimulus when a single parafoveal word is viewed briefly. Not only does parafoveal viewing provide reduced retinal resources as a function of receptor and ganglion types, density, and distribution, but, in contrast to foveal viewing, only one contralateral hemisphere initially encodes the input. The present investigation therefore had two purposes. One was to identify if the difference in word processing between foveal and parafoveal viewing can be attributed to the role of one hemisphere versus two hemispheres in the initial encoding of the word. The other was to identify more clearly how, in addition to motivation, word characteristics, like frequency and category of word content, affect parafoveal, relative to foveal, word processing.

\section{GENERAL METHOD}


5 women. As in all the prior studies, the subjects were recruited from classes as volunteers to fulfill part of their research requirements. Each subject was assigned randomly to one or the other motivation condition within each study. All subjects had 20/20 or corrected vision. Words were presented for $10 \mathrm{msec}$ by means of a Gerbrands three-field tachistoscope. Luminosity was $6.54 \mathrm{~mL}$ in the three fields, which were lit throughout testing. Two words were repeated in random alternation until a given word was correctly recognized on two consecutive presentations. Each word was shown parafoveally, between $2.25^{\circ}$ and $4.25^{\circ}$ from center fixation. All subjects were right-handed and were tested at their usual lunch time. A Gerbrands system was used in the manner of the prior studies, with a voice microphone and a clock counter measuring vocal reaction times. Words were printed horizontally in black capital letters. The same words were used in Experiments 1, 3, and 4, whereas the words of prior studies were used in Experiment 2.

\section{Experiments 1 and 2}

Contrary to the prior parafoveal studies (Ferguson, 1988, 1989), in which the words were not presented equally often in both visual fields, in Experiments 1 and 2 of the present investigation, the words were presented equally often across subjects. Thus, visual field (VF) effects could be separately analyzed. For Experiment 1 , only three of the previously used words were employed: hag and woe as negatively emotional words, and pie as a food word. Because the prior category of animal words had yielded somewhat uncertain effects, the present experiments utilized only the two categories of food words and negatively emotional words. The eight words were pie, yam, nut, fry, hag, woe, gun, and $f l u$. Due to a design error, the high- and low-frequency words were not presented equally often in each VF for each subject, even though the categories were presented equally often for each subject. Accordingly, caution was required for analyzing the frequency data in Experiment 1 . In Experiment 2, such analysis was readily available, with frequency and category analyzed separately for each VF. The words used in the earlier studies (Ferguson, 1988, 1989) were used in Experiment 2: pie, gum, rye, cob, hag, woe, sin, and pus.

As in the prior studies, words were unpredictably shown in one or the other VF, and the subjects fixated on the center $X$ at all times. When a word in one VF was recognized to the criterion of two consecutive correct recognitions, a new word appeared in that VF, regardless of what occurred in the other VF. A central-fixation $X$ was visible before and after word exposure. On some "catch" trials, the center $\mathrm{X}$ was on during word exposure, and, to ensure center fixation, the subjects were periodically asked whether or not the center $X$ had remained on. This procedure had been effective in the prior studies.

\section{Experiments 3 and 4}

The same words used in Experiment 1 were used in Experiments 3 and 4; however, instead of being presented in one VF, the word appeared concurrently in both VFs. This permitted assessing the role of two hemispheres, rather than one hemisphere, initially processing the parafoveal word.
In Experiment 3, center fixation was prescribed according to the procedure used in Experiments 1 and 2, with a center $X$ and catch trials. However, a large number of subjects realized, partway through the list of words, that the two VFs each contained the identical word, and many subjects consequently "cheated," looking right or left, thus viewing the words foveally instead of parafoveally. To prevent this, Experiment 4 used a more stringent control. On every trial, rather than merely on random catch trials, the subjects had to indicate whether the center $X$ was on or off during word exposure and, instead of merely a blank or an X, four alternatives were possible: an $\mathrm{X}$, a blank, the digit 8 , or the digit 5. Between word exposures, the subjects fixated on a center dot instead of on a center $X$, and they were told that the experiment would be discontinued should errors in identification occur concerning the presence or absence of the center $\mathbf{X}$ when the word was shown. Verbal reports after testing, as well as inspection of the regularity in the data, revealed that, under these more stringent conditions, the subjects fixated on the center for all trials. As done in catch trials with the other studies, the subjects first reported the word shown and then indicated whether the center $\mathrm{X}$ had or had not been present during word exposure.

\section{RESULTS AND DISCUSSION}

To permit comparison with the prior studies, although the subjects were shown a new word only after two consecutive correct recognitions, the data for the present investigation were analyzed for first correct recognition.

As can be seen in Tables 1 and 2, motivation had no significant effect. This replicates the earlier parafoveal studies, which failed to find that hungry subjects recognize the words significantly sooner than do satiated subjects (Ferguson, 1988, 1989). Thus, the difference between parafoveal and foveal word viewing was again evident in that, unlike the foveal conditions (Erwin \& Ferguson, 1979; Ferguson, 1983, 1988), the parafoveal word viewing was not facilitated by increased motivation.

Two results from the present investigation are striking. One is that any significant effects from word characteristics under parafoveal viewing are evident only in the right, not the left, VF. As seen in Table 1, when data are separately analyzed for each VF, in one experiment (Experiment 1), category of words was significant in the right VF (RVF), with negatively emotional words requiring far more trials than food words for first correct recognition. In the other experiment (Experiment 2), significant interactions were found in the RVF that involved word-frequency charac-

Table 1

Word-Frequency, Category, and Motivation Effects Under Rightand Left-Field Viewing

\begin{tabular}{|c|c|c|c|c|c|c|c|c|}
\hline \multirow[b]{3}{*}{ Subjects } & \multicolumn{4}{|c|}{ LVF } & \multicolumn{4}{|c|}{ RVF } \\
\hline & \multicolumn{2}{|c|}{ Food Words } & \multicolumn{2}{|c|}{ Neg. Emot. } & \multicolumn{2}{|c|}{ Food Words } & \multicolumn{2}{|c|}{ Neg. Emot. } \\
\hline & Low & High & Low & High & Low & High & Low & High \\
\hline \multicolumn{9}{|c|}{ Experiment 1} \\
\hline $\begin{array}{l}\text { Hungry } \\
\text { Satiated }\end{array}$ & $\begin{array}{l}6.25 \\
8.44\end{array}$ & $\begin{array}{l}6.25 \\
4.25\end{array}$ & $\begin{array}{l}4.31 \\
8.25\end{array}$ & $\begin{array}{l}5.12 \\
7.81\end{array}$ & $\begin{array}{l}4.69 \\
2.62\end{array}$ & $\begin{array}{l}4.06 \\
4.62\end{array}$ & $\begin{array}{l}8.75 \\
6.69\end{array}$ & $\begin{array}{l}8.06 \\
9.12\end{array}$ \\
\hline \multicolumn{9}{|c|}{ Experiment 2} \\
\hline $\begin{array}{l}\text { Hungry } \\
\text { Satiated }\end{array}$ & $\begin{array}{l}3.62 \\
5.88\end{array}$ & $\begin{array}{l}4.62 \\
5.12\end{array}$ & $\begin{array}{l}4.62 \\
4.94\end{array}$ & $\begin{array}{l}5.94 \\
5.31\end{array}$ & $\begin{array}{l}7.50 \\
6.44\end{array}$ & $\begin{array}{l}3.38 \\
4.44\end{array}$ & $\begin{array}{l}5.31 \\
3.62\end{array}$ & $\begin{array}{l}4.62 \\
9.88\end{array}$ \\
\hline
\end{tabular}

Note-All values are the mean number of presentations to correct word recognition with 10-msec word exposure. LVF = left visual field, RVF = right visual field, Neg. Emot. = negatively emotional words, Low $=$ low-frequency words, and High $=$ high-frequency words. 
Table 2

Word-Frequency, Category, and Drive Effects Under Double-Field Parafoveal Viewing

\begin{tabular}{|c|c|c|c|c|c|c|c|c|}
\hline \multirow[b]{3}{*}{ Subjects } & \multicolumn{4}{|c|}{ Experiment 3} & \multicolumn{4}{|c|}{ Experiment 4} \\
\hline & \multicolumn{2}{|c|}{ Food Words } & \multicolumn{2}{|c|}{ Neg. Emot. } & \multicolumn{2}{|c|}{ Food Words } & \multicolumn{2}{|c|}{ Neg. Emot. } \\
\hline & Low & High & Low & High & Low & High & Low & High \\
\hline Hungry & 2.85 & 3.60 & 2.60 & 1.95 & 3.70 & 3.40 & 4.35 & 2.85 \\
\hline Satiated & 2.30 & 3.25 & 10.15 & 4.30 & 2.75 & 3.00 & 5.20 & 4.40 \\
\hline
\end{tabular}

Note-All values are the mean number of presentations to correct word recognition with 10 -msec word exposure. Neg. Emot. = negatively emotional words, Low = low-frequency words, and High = high-frequency words.

teristics. Each VF was separately analyzed for first correct trial data by a $2 \times 2 \times 2$ analysis of variance (ANOVA) with two levels each for motivation, frequency, and category. Because of the incomplete counterbalancing for category and frequency across subjects in Experiment 1, a conservative analysis that treated all variables as between subjects was done. No significant effects or interactions were found for left VF (LVF); however, for RVF, category was significant $\left[F(1,120)=9.08, M S_{\mathrm{e}}=60.91\right.$, $p=.003]$. No other effects or interactions were significant. For Experiment 2, the $2 \times 2 \times 2$ ANOVA for each VF treated category and frequency as within-subject variables, and motivation was treated as a between-subject variable. For LVF, none of the effects or interactions were significant. For RVF, the two significant interactions involving frequency were motivation $\times$ frequency $[F(1,30)$ $\left.=5.62, M S_{\mathrm{e}}=29.23, p=.024\right]$ and category $\times$ frequency $\left[F(1,30)=5.36, M S_{\mathrm{e}}=51.01, p=.028\right]$. None of the main effects were significant, nor were any of the other interactions.

The second major finding was that even when initially two hemispheres concurrently process the words parafoveally, the usual effects for foveal word processing do not occur. Under circumstances in which some of the word viewing was definitely foveal due to subjects' "cheating," as in Experiment 3, the tendency for hunger to facilitate word recognition was evident. A $2 \times 2 \times 2$ ANOVA revealed a significant motivation $\times$ category interaction $\left[F(1,18)=5.87, M S_{\mathrm{e}}=24.59, p=.026\right]$. As can be seen in Table 2 , for the less readily recognized negatively emotional words, the satiated subjects had poorer performance than did the hungry subjects. As was also found in the RVF for Experiment 2, which utilized a somewhat different set of words, the frequency $\times$ category interaction was also significant for Experiment 3 $\left[F(1,18)=7.10, M S_{\mathrm{e}}=11.99, p=.016\right]$. Far more muted effects were found with double-field viewing when parafoveal viewing was clearly involved, as in Experiment 4 . Although a motivation $\times$ category interaction occurred in Experiment 4 similar to that in Experiment 3, the interaction was not significant under strict parafoveal viewing. Because hungry subjects did worse than they had done in Experiment 3 and satiated subjects did better than their counterpart in Experiment 3, the interaction was present but only marginally significant $[F(1,18)=$ $3.22, M S_{\mathrm{e}}=5.45, p=.089$ ]. A marginally significant effect for category was found $\left[F(1,18)=3.58, M S_{e}=\right.$ $5.45, p=.075]$, with negatively emotional words rec- ognized less readily than the food words. This mirrored the significant effect in RVF of Experiment 1 with the same words.

When a single word is viewed at a given time, unlike the condition for normal reading, processing of words under single-field parafoveal viewing is qualitatively different than under foveal viewing. This can be seen by the lack of significant effects for motivation, and largely for interletter and word frequency, under single-field parafoveal viewing. The letter font and size of the words in the present experiments were identical to those used in a prior foveal study (Ferguson, 1988), and yet the effects of motivation and word characteristics differ in major ways for the two types of viewing. Moreover, the differences do not appear to be primarily a function of the single cerebral hemisphere's initially processing the word. Although the double-field parafoveal experiment in which no foveal viewing was evident (Experiment 4) did reveal muted effects of motivation and word category, to suggest that part of the problem with parafoveal viewing lies in the reduced resources available when one hemisphere, rather than two hemispheres, initially encodes the word, the double-hemisphere explanation cannot adequately account for the difference between foveal and parafoveal word processing. Even when the two hemispheres concurrently processed the parafoveal input, the word-recognition data far more resembled the single-hemisphere data than it resembled the foveal data of prior studies.

Essentially, when all the studies to date are taken together (Ferguson, 1988, 1989, and the present four experiments), the evidence is overwhelming that word processing for foveal viewing is in many ways different from that for parafoveal viewing. The most notable difference lies in the role of motivation, and in the way frequency characteristics do not affect parafoveal word processing the way they do foveal word processing. That is, low-frequency words are typically less readily recognized than are highfrequency words (Ferguson, 1983), but this was not the case for the parafoveal data in the present experiments.

The fact that parafoveal viewing in the LVF fails to reveal any of the effects ordinarily found for foveal viewing, whereas some of the effects are evident in RVF parafoveal viewing, is congruent with all that is known about the language specialization of the left hemisphere. With single-field viewing, the contralateral hemisphere initially encodes the information. Thus, the fact the RVF-left hemisphere initial encoding, but not the LVF-right hemisphere initial encoding, was found in the present studies 
to follow some of the processing characteristics of foveal viewing meshes with what is known about hemispheric specialization for language (Hellige, 1982). It is noteworthy that, in spite of the RVF processing resembling foveal processing, major differences remain, and these cannot be attributed alone to hemisphere characteristics. Rather, the reduction in resources, which are available for parafoveal, in contrast to foveal, viewing, qualitatively alters the way word information is processed. Further studies are underway to delineate some of the possible sources for these processing differences and to identify more fully the types of differences that occur between parafoveal and foveal word processing.

\section{REFERENCES}

BalotA, D. A. (1990). The role of meaning in word processing. In D. A. Balota, G. Flores D'Arcais, \& K. Rayner (Eds.), Comprehension processes in reading (pp. 9-32). Hillsdale, NJ: Erlbaum.

BALOtA, D. A., \& RAYNER, K. (1991). Word recognition processes in foveal and parafoveal vision. In D. Besner \& G. Humphreys (Eds.), Basic processes in reading: Visual word recognition (pp. 198-232). Hillsdale, NJ: Erlbaum.

Erwin, R. J., \& Ferguson, E. D. (1979). The effect of food and water deprivation and satiation on recognition. American Journal of Psychology, 92, 611-626.

Ferguson, E. D. (1983). The effect of motivation and word characteristics on recognition. American Joumal of Psychology, 96, 253-266.

FERGUSON, E. D. (1988). Motivational influences on word recognition: I. Foveal and parafoveal viewing. Bulletin of the Psychonomic Society, 26, 203-205.

FERGUSON, E. D. (1989). Motivational influences on word recognition: II. Affective coding. Bulletin of the Psychonomic Society, 27, 307-310. Hellige, J. B. (Ed.) (1982). Cerebral hemisphere asymmetry: Method, theory, and application. New York: Praeger.

THORNDIKE, E. E., LORGE, I. (1944). The teacher's book of 30,000 words. New York: Columbia University Press.

UNDERWOOD, B. J., \& SCHUlz, R. W. (1960). Meaningfulness and verbal learning. Philadelphia: Lippincott.

(Manuscript received July 15, 1991.) 